\title{
Lipotoxic Palmitate Impairs the Rate of $\beta$-Oxidation and Citric Acid Cycle Flux in Rat Neonatal Cardiomyocytes
}

\author{
Taha Haffara,b Ali Akoumia Nicolas Bousette ${ }^{a, c}$ \\ aMontreal Heart Institute, bUniversite de Montréal, Department of Biomedical Science, 'Universite de \\ Montréal, Department of Surgery, Montréal, Canada
}

\section{Key Words}

Metabolism • Lipotoxicity • Fatty acids • Cpt1b • $\beta$-oxidation • Citric acid cycle

\begin{abstract}
Background/Aims: Diabetic hearts exhibit intracellular lipid accumulation. This suggests that the degree of fatty acid oxidation (FAO) in these hearts is insufficient to handle the elevated lipid uptake. We previously showed that palmitate impaired the rate of FAO in primary rat neonatal cardiomyocytes. Here we were interested in characterizing the site of FAO impairment induced by palmitate since it may shed light on the metabolic dysfunction that leads to lipid accumulation in diabetic hearts. Methods: We measured fatty acid oxidation, acetyl-CoA oxidation, and carnitine palmitoyl transferase (Cpt1b) activity. We measured both forward and reverse aconitase activity, as well as NAD+ dependent isocitrate dehydrogenase activity. We also measured reactive oxygen species using the 2', 7'-Dichlorofluorescin Diacetate (DCFDA) assay. Finally we used thin layer chromatography to assess diacylglycerol (DAG) levels. Results: We found that palmitate significantly impaired mitochondrial $\beta$-oxidation as well as citric acid cycle flux, but not Cpt1b activity. Palmitate negatively affected net aconitase activity and isocitrate dehydrogenase activity. The impaired enzyme activities were not due to oxidative stress but may be due to DAG mediated PKC activation. Conclusion: This work demonstrates that palmitate, a highly abundant fatty acid in human diets, causes impaired $\beta$-oxidation and citric acid cycle flux in primary neonatal cardiomyocytes. This metabolic defect occurs prior to cell death suggesting that it is a cause, rather than a consequence of palmitate mediated lipotoxicity. This impaired mitochondrial metabolism can have important implications for metabolic diseases such as diabetes and obesity.
\end{abstract}

\section{Introduction}

(C) 2016 The Author(s)

Published by S. Karger AG, Basel

Cardiac disease is the primary cause for morbidity and mortality in the diabetic population [1]. Since diabetes impairs glucose uptake and oxidation there is a compensatory increase in fatty acid uptake. This in turn leads to cardiac lipid accumulation and ensuing lipotoxicity. Several studies have pointed to the role of lipotoxicity in diabetic cardiomyopathy [2-7]. Furthermore, several studies have shown a correlation between the degree of lipid accumulation and cardiac dysfunction in human diabetic hearts [8-11].

Nicolas Bousette, PhD

KARGER
Université de Montréal, Department of Surgery, Montreal Heart Institute, 5000, rue Bélanger, Suite S-4100, Montréal (Québec), H1T 1C8, (Canada)

E-Mail nicolas.bousette@umontreal.ca 
Lipids accumulate in the diabetic heart because uptake exceeds lipid clearance. Lipid clearance in the heart is primarily dependent on fatty acid oxidation (FAO). FAO begins by carnitine palmitoyl transferase (Cpt1b) mediated FA uptake into mitochondria. Once inside the mitochondrion fatty acids are oxidized by the progressive removal of 2 carbons with each cycle of $\beta$-oxidation. The resultant 2-carbon acetyl-CoA is fed into the citric acid cycle (CAC) where it is oxidized to $\mathrm{CO}_{2}$ with the consequent production of reducing equivalents, including $\mathrm{NADH}$ and $\mathrm{FADH}_{2}$. The reducing equivalents are then fed into the electron transport chain (ETC), which drives oxidative phosphorylation.

Some models of diabetic cardiomyopathy including leptin or leptin receptor deficient mice have shown that $\beta$-oxidation is actually increased in the diabetic heart $[12,13]$. However studies in other models show either no change $[14,15]$ or decreased oxidation $[16,17]$. These discrepancies might be explained by differences in species, concentration of fatty acid used to measure oxidation, and/or animal age. For instance, two studies evaluating diabetic humans as well as a study of a porcine model of diabetes all showed decreased FAO with diabetes [18-20], possibly indicating a difference between rodents and higher order mammalians. Another study showed that diabetic rat hearts exhibited significantly enhanced FAO at low concentrations of FA, but FAO was significantly depressed at high concentrations [21]. This is important because serum FA levels are generally higher in diabetics. Finally, age and associated pathological sequelae may be an important determinant of FAO in diabetics as older diabetic rats exhibited significant reductions in FAO compared to both age matched controls and younger diabetic rats [22]. Another potentially limiting factor is that many of these studies only measured $\beta$-oxidation, which is merely the first half of FAO and does not take into consideration downstream steps including acetyl-CoA oxidation in the CAC nor the components of the electron transport chain (ETC). Thus it is interesting that several studies show impaired mitochondrial function in the heart of diabetic humans and animals as evidenced by decreased fatty acid driven respiration [20, 23-27]. These latter studies implicate potential deficiencies in either events upstream of $\beta$-oxidation, such as mitochondrial uptake (i.e. Cpt1b activity) or downstream events including citric acid cycle flux or the electron transport chain. In support of the notion that diabetes causes metabolic derangements downstream of $\beta$-oxidation, Lin et al. found an impairment in net aconitase enzyme activity in the diabetic rat heart [28]. Aconitase is a key CAC enzyme responsible for the conversion of citrate to isocitrate.

It should be noted that an increase in $\beta$-oxidation without a concomitant increase in citric acid cycle flux would nonetheless compromise metabolism of the heart by impairing energy production and/or by providing a surplus of substrates for re-synthesis of fatty acids. Regardless of whether or not fatty acid oxidation is increased in diabetic hearts, the fact remains that diabetic hearts accumulate lipid suggesting that the degree of FAO, whatever it may be, is not sufficient in the face of elevated FA uptake. This leads to the question as to whether increasing FAO would attenuate lipotoxicity in diabetic cardiomyopathy.

Interestingly, we have shown that increasing fatty acid oxidation is associated with attenuated lipotoxicity in primary cardiomyocytes [29]. Specifically we previously showed that palmitate, a lipotoxic FA, impaired fatty acid oxidation in primary rat neonatal cardiomyocytes (NCMs) and that enhancing fatty acid oxidation attenuated palmitatemediated lipotoxicity. In contrast, we also demonstrated that impairing fatty acid oxidation induced lipotoxicity. Here we aimed to determine how palmitate impairs FAO in primary cardiomyocytes. We found that palmitate impairs both $\beta$-oxidation and citric acid cycle flux, but not the uptake of FA into mitochondria.

\section{Materials and Methods}

Rat neonatal cardiomyocytes (NCM) culture

NCMs were isolated from hearts of 1-day-old rats. Hearts were isolated and tissue was washed several times in digestion buffer containing $137 \mathrm{mM} \mathrm{NaCl}, 5.36 \mathrm{mM} \mathrm{KCl}, 0.81 \mathrm{mM} \mathrm{MgSO}_{4}, 5.55 \mathrm{mM}$ dextrose, 0.44 


\section{Cellular Physiology Cell Physiol Biochem 2016;40:969-981 \begin{tabular}{l|l} 
and Biochemist 10.1159/000453154 & $\begin{array}{l}\text { C) 2016 The Author(s). Published by S. Karger AG, Basel } \\
\text { www.karger.com/cpb }\end{array}$ \\
\hline Published online: December 07, 2016
\end{tabular}}

Haffar et al.: Palmitate Impairs Lipid Metabolism

$\mathrm{mM} \mathrm{KH} \mathrm{PO}_{4}, 0.34 \mathrm{mM} \mathrm{Na}_{2} \mathrm{HPO}_{4}, 20 \mathrm{mM}$ HEPES, and $50 \mu \mathrm{g} / \mathrm{ml}$ gentamicin. Tissue was then incubated in digestion buffer with collagenase (50units $/ \mathrm{ml}$ ). Cells in suspension resulting from the tissue digestion were transferred to ice cold FBS every 10-20 min. This step was repeated until all tissue was digested. Cells in FBS were pelleted and then re-suspended in DMEM containing 10\% FBS. Cells were plated in petri dish for $1 \mathrm{~h}$ at $37^{\circ} \mathrm{C}$ to allow fibroblasts to adhere. The non-adherent cardiomyocytes were then plated at a density of $\sim 40,000$ cells $/ \mathrm{cm}^{2}$. NCMs were cultured in DMEM/F12 + 2\% FBS + $100 \mu$ M bromodeoxyuridine for a minimum of 7 days prior to treatments to allow for maturation and the switch from primarily glucose oxidation to primarily fatty acid oxidation.

Fatty acid preparation

Oleate (Sigma, 07501) was solubilized in anhydrous methanol while palmitate (Sigma, P9767) was solubilized in $150 \mathrm{mM} \mathrm{NaCl}$ by heating to $70^{\circ} \mathrm{C}$. Both fatty acids were then complexed to bovine serum albumin (BSA) in a 6:1 ratio as previously described [29].

Fatty acid oxidation (FAO) assay

Cells were pretreated with $300 \mu \mathrm{M}$ oleate or $300 \mu \mathrm{M}$ palmitate for $8 \mathrm{~h}$. Media was removed and cells were washed 2 times with warm PBS. Radiolabelled oleate (American Radio-chemicals, ARC 0297) or palmitate (American Radio-chemicals, ARC 0172A) were solubilized in non-bicarbonate assay buffer (114 $\mathrm{mM}$ of $\mathrm{NaCl}, 4.7 \mathrm{mM}$ of $\mathrm{KCl}, 1.2 \mathrm{mM}$ of $\mathrm{KH}_{2} \mathrm{PO}_{4}, 1.2 \mathrm{mM}$ of $\mathrm{MgSO}_{4}, 0.5 \%$ fatty acid free BSA) and cells were incubated with $0.4 \mu \mathrm{Ci}$ of ${ }^{14} \mathrm{C}$ - oleic acid or ${ }^{14} \mathrm{C}$ - palmitic acid for 2 hours. To determine $\mathrm{CO}_{2}$ production $6 \mathrm{~N}$ $\mathrm{HCl}$ was added to cell media and $\mathrm{CO}_{2}$ was captured by a filter paper soaked in $2 \mathrm{M} \mathrm{NaOH}$. The filter paper was then added to a scintillation vial with scintillation fluid and radioactivity was read with the Beckman LS6500 scintillation counter.

To obtain acid soluble metabolites (ASM) cardiomyocytes were collected by trypsinization and resuspended in $1 \mathrm{M}$ perchloric acid and then homogenized using 25G gauge needle. Samples were centrifuged at $17,000 \mathrm{~g}$ and the supernatant was added to scintillation fluid and counted using Beckman LS6500 scintillation counter.

To obtain water soluble metabolites (WSM), cardiomyocytes were re-suspended in 250M sucrose/ $50 \mathrm{M}$ tris buffer and homogenized with $25 \mathrm{G}$ gauge needle. Water saturated butanol was added to each sample and butanol/water phases were separated by centrifugation at $1000 \mathrm{~g}$ for $5 \mathrm{~min}$. The water phase was added to scintillation fluid and counted using Beckman LS6500 scintillation counter. The radioactivity from samples was normalized to radioactivity of loading control for each radiolabelled fatty acid (i.e. ${ }^{14} \mathrm{C}$ oleate and ${ }^{14} \mathrm{C}$ - palmitate) and to protein concentration. Data are expressed as picomols $/ \mu \mathrm{g}$ protein $/ \mathrm{min}$.

\section{Acetyl-CoA oxidation assay}

This assay was done identically to the fatty acid oxidation assay described above except cells were exposed to ${ }^{14} \mathrm{C}$-Acetate for 1 hour (American Radio-chemicals, ARC0101) instead of radiolabelled fatty acids. Radioactivity from samples was normalized to radioactivity of loading control and to protein concentration. Data are expressed as picomols/ $\mu$ g protein $/ \mathrm{min}$.

\section{Aconitase activity assay}

Aconitase reverse activity was measured by quantifying the synthesis rate of cis-aconitate (Abcam, ab109712). Briefly, crude mitochondria were isolated from cardiomyocytes using buffer containing 10 $\mu \mathrm{M}$ tris-Mops, $1 \mu \mathrm{M}$ EGTA/tris and $200 \mu \mathrm{M}$ sucrose. $50 \mu \mathrm{g}$ of crude mitochondria were re-suspended in aconitase preservation buffer with isocitrate. Cis-aconitate level was measured by reading the absorbance at $240 \mathrm{~nm}$ for $30 \mathrm{~min}$ at $37^{\circ} \mathrm{C}$. Aconitase forward activity was carried out identically however citrate was used as substrate in place of isocitrate. Data are presented as change $(\Delta)$ in absorbance from baseline to the end of the experiment.

\section{Isocitrate dehydrogenase (IDH) activity assay}

IDH activity was measured (Abcam, ab102528). Briefly, cardiomyocytes were treated with oleate or palmitate for $8 \mathrm{~h}$ then isolated by trypsinization. Cells were re-suspended in supplied buffer containing $\mathrm{NAD}+$ and NADH formation was determined by measuring the absorbance at $450 \mathrm{~nm}$ for 30 minutes at $37^{\circ} \mathrm{C}$. Data are presented as change $(\Delta)$ in absorbance from baseline to the end of the experiment. 


\section{Cellular Physiology Cell Physiol Biochem 2016;40:969-981 \begin{tabular}{l|l} 
and Biochemistry Published online: December 07, 2016 & $\begin{array}{l}\text { C) 2016 The Author(s). Published by S. Karger AG, Basel } \\
\text { www.karger.com/cpb }\end{array}$
\end{tabular}}

Haffar et al.: Palmitate Impairs Lipid Metabolism

Carnitine palmitoyl transferase (Cpt1b) activity assay

$\mathrm{Cpt1b}$ activity assay was carried out as previously described [30]. Briefly, cardiomyocytes were treated with $300 \mathrm{uM}$ palmitate or $300 \mathrm{uM}$ oleate for $8 \mathrm{~h}$ followed by [1- $\left.\mathrm{C}^{14}\right]$ Carnitine for $30 \mathrm{~min}$. Radiolabeled acylcarnitine was separated from radiolabeled carnitine using butanol-water phase separation. Acyl-carnitine levels, indicating cpt1b activity, were measured by a scintillation counter (Beckman LS6500). Specifically, organic phase radioactivity was normalized to loading control radioactivity and protein concentration and expressed as picomol/ $\mu$ g protein / $\mathrm{min}$.

\section{2', 7'-Dichlorofluorescin Diacetate (DCFDA) assay}

The DCFDA assay was carried out as previously described with slight modifications [31]. Briefly, cardiomyocytes were treated with oleate or palmitate for $8 \mathrm{~h}$ and then cells were washed twice with KrebsRinger HEPES buffer then incubated with $10 \mu \mathrm{M}$ DCFH-DA. Fluorescence was read (485 nm excitation and $530 \mathrm{~nm}$ emission) for $30 \mathrm{~min}$ at $37^{\circ} \mathrm{C}$ using the Synergy 2 microplate reader. Data are presented as change $(\Delta)$ in fluorescence from baseline to the end of the experiment.

Thin Layer Chromatography (TLC)

Lipid samples were isolated by the Bligh and Dyer method then spotted on a silica gel plate. The silica plate was then placed in a TLC tank allowing the lipids to migrate with the mobile phase by capillary action. The TLC tank was equilibrated with $150 \mathrm{ml}$ of 75:75:1.5 Chloroform: DiethylEther: Acetic acid. Lipid spots were then visualized on silica plate by rhodamine labeling. Mono-, Di-, \& Triglyceride Mix (Sigma, 17871AMP) was used as standard.

\section{Western blotting}

Western blotting was carried out as previously described, [29, 32] with the anti-IDH3a antibody (1/200 dil. Santa Cruz biotechnology, SC-514358), 4-HNE antibody (1/1000, Abcam, ab46545) Histone H3 antibody (Santa Cruz biotechnology, SC-10809), and the $\alpha$-tubulin (Santa Cruz biotechnology, SC-23948).

Fatty acid uptake assay

Cardiomyocytes were pre-treated with either $300 \mu \mathrm{M}$ oleate or palmitate for 8 hours. Following this cardiomyocytes were exposed to $0.5 \mathrm{UCi} / \mathrm{ml}$ of radiolabeled oleate or palmitate (in a buffer containing 114 $\mathrm{mM}$ of $\mathrm{NaCl}, 4.7 \mathrm{mM}$ of $\mathrm{KCl}, 1.2 \mathrm{mM}$ of $\mathrm{KH}_{2} \mathrm{PO}_{4}, 1.2 \mathrm{mM}$ of $\mathrm{MgSO}_{4}$ ) for $15 \mathrm{~min}$. Cells were then washed twice in ice-cold PBS and then isolated by trypsinization. Uptake of radiolabelled fatty acids was measured by scintillation counter (Beckman LS6500) and normalized to protein abundance.

\section{Statistical analysis}

All data are presented as mean \pm standard error. Statistics were carried out with StatGrapher software. Students T-test was used for two-group comparisons. Multiple groups were compared using one-way ANOVA with Tukey post-hoc test. Data involving multiple groups and multiple conditions (e.g. TLC analysis) were analysed by two-way ANOVA with Tukey post-hoc test.

\section{Results}

\section{Palmitate impairs complete FAO but not Cpt1b activity}

Here we demonstrated that an 8-hour treatment of $300 \mu \mathrm{M}$ palmitate impaired complete FAO in primary neonatal cardiomyocytes (NCMs) compared to cells treated with an equivalent time and dose of oleate (Fig. 1A). Specifically, NCMs treated with palmitate had a marked decrease in $\mathrm{CO}_{2}$ production compared to oleate treated cells. A similar degree of impairment was observed in cells treated with palmitate + carnitine compared to cells treated with oleate + carnitine (Fig. 1B). To verify that the difference was not due to altered uptake rates between cells pre-treated with oleate compared to those pre-treated with palmitate, we evaluated uptake rates of radiolabelled oleate or palmitate following 8 hour pre-treatment of either $300 \mu \mathrm{M}$ oleate or $300 \mu \mathrm{M}$ palmitate, respectively. We found no difference in uptake rates between the two different pre-treatments (Fig. 1D). 
Fig. 1. Palmitate impairs complete fatty acid oxidation in primary neonatal cardiomyocytes (NCMs). (A) Graph showing significantly decreased $\mathrm{CO} 2$ production in NCMs treated with $300 \mu \mathrm{M}$ palmitate for 8 hours compared to those treated with $300 \mu \mathrm{M}$ oleate. (B) Graph showing significantly decreased $\mathrm{CO} 2$ production in NCMs treated with $300 \mu \mathrm{M}$ palmitate $+250 \mu \mathrm{M}$ carnitine for 8 hours compared to those treated with $300 \mu \mathrm{M}$ oleate $+250 \mu \mathrm{M}$ carnitine. (C) Graph showing no difference in Cpt1b activity (measured as acyl-carnitine production) between NCMs treated with $300 \mu \mathrm{M}$ palmitate compared to NCMs treated with $300 \mu \mathrm{M}$ oleate for 8 hours. (D) Graph showing no difference in uptake of radiolabelled oleate or palmitate in NCMs pre-treated with either $300 \mu \mathrm{M}$ oleate or $300 \mu \mathrm{M}$ palmitate for 8 hours, respectively.

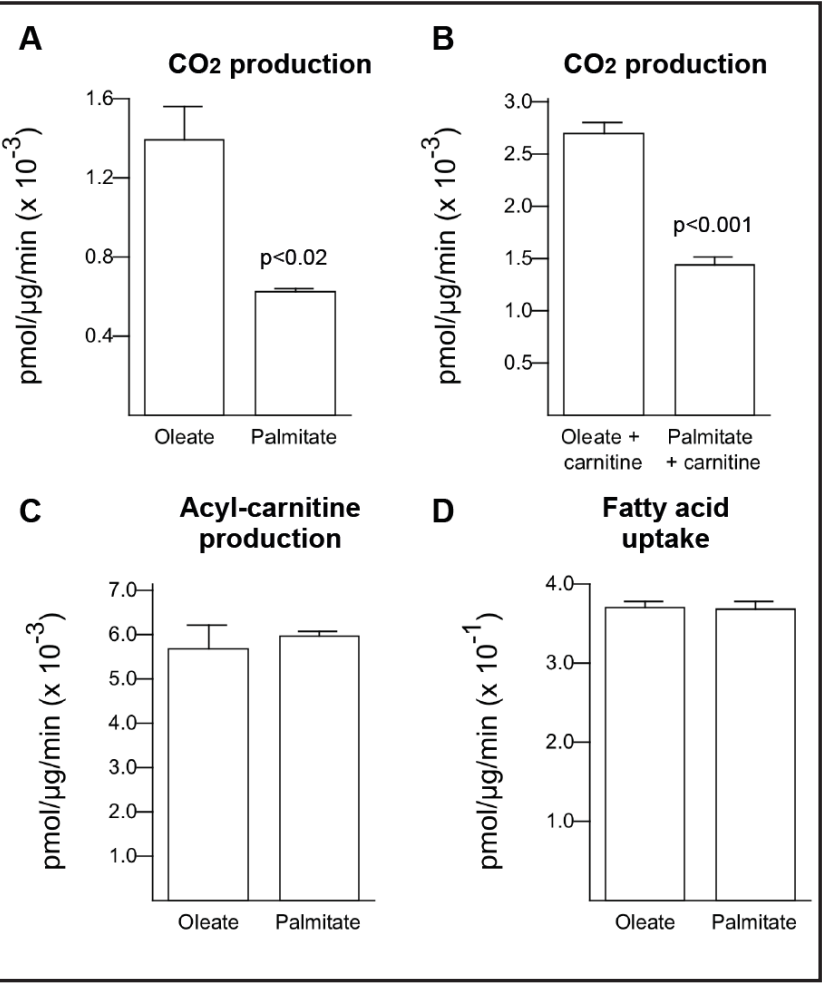

Fig. 2. Palmitate impairs $ß$-oxidation in primary neonatal cardiomyocytes (NCMs). (A) Graph showing significantly decreased water soluble metabolites (WSMs) from NCMs treated with $300 \mu \mathrm{M}$ palmitate for 8 hours compared to those treated with 300 $\mu \mathrm{M}$ oleate. (B) Graph showing significantly decreased WSMs from NCMs treated with $300 \mu \mathrm{M}$ palmitate $+250 \mu \mathrm{M}$ carnitine for 8 hours compared to those treated with 300 $\mu \mathrm{M}$ oleate $+250 \mu \mathrm{M}$ carnitine.
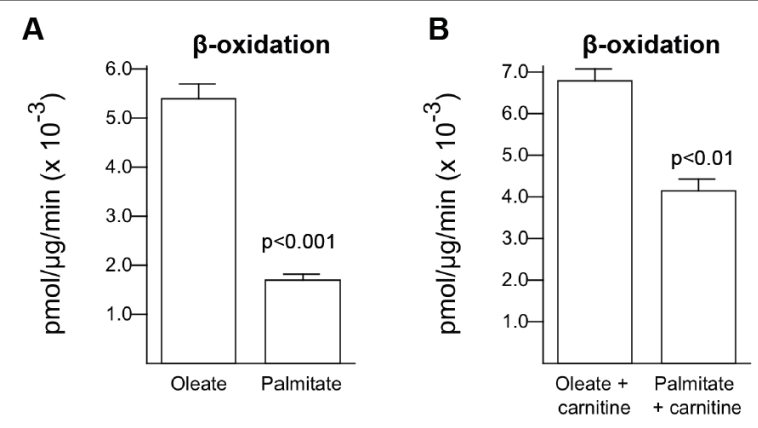

We previously showed that Cpt1b protein content was not altered under these conditions [33]. Therefore, here we assessed if palmitate decreased Cpt1b activity rather than expression. We evaluated Cpt1b activity by measuring the production of acyl-carnitines in NCMs pre-treated with either oleate or palmitate. We found that Cpt1b activity was not altered by palmitate (Fig. 1C). This is supported by the observation that co-administration of carnitine increases FAO to the same degree in either oleate or palmitate treated cells (i.e. both $\sim 2$ fold over basal levels of each respective fatty acid without carnitine, data not shown). This suggests that palmitate mediated impairment of FAO occurs downstream of Cpt1b.

Similar results were found in $\mathrm{H} 9 \mathrm{C} 2$ cardiomyoblasts. Indeed, palmitate significantly reduced $\mathrm{CO}_{2}$ production but did not have any effect on $\mathrm{Cpt} 1 \mathrm{~b}$ activity (data not shown).

\section{Palmitate impairs $\beta$-oxidation}

To test the effect of palmitate on $\beta$-oxidation we quantified acid soluble metabolites (ASM), an established technique for assessing the degree of $\beta$-oxidation by quantifying the production of fatty acid metabolites with 6 or less carbons. Because the radiolabelled fatty acid contains the label on the first carbon, measured ASM metabolites should represent acetyl-CoA produced by $\beta$-oxidation of fatty acids and/or intermediates of the citric acid 


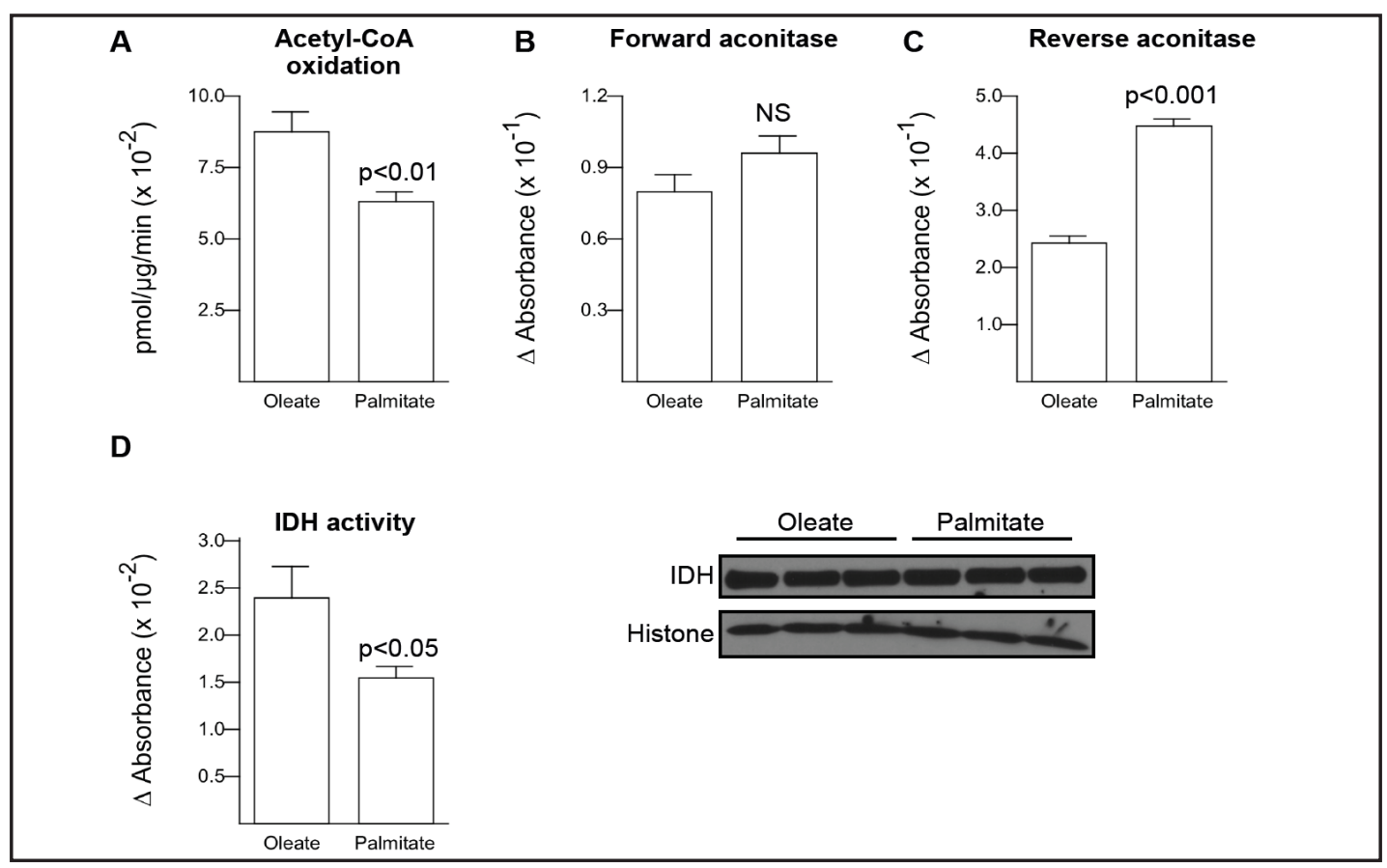

Fig. 3. Palmitate impairs citric acid cycle (CAC) flux in primary neonatal cardiomyocytes (NCMs). (A) Graph showing significantly decreased CO2 production from radiolabelled acetyl-CoA in NCMs treated with 300 $\mu \mathrm{M}$ palmitate for 8 hours compared to those treated with $300 \mu \mathrm{M}$ oleate. (B) Graph showing no significant difference in forward aconitase activity in NCMs treated with $300 \mu \mathrm{M}$ palmitate for 8 hours compared to those treated with $300 \mu \mathrm{M}$ oleate. (C) Graph showing significantly increased reverse aconitase activity in NCMs treated with $300 \mu \mathrm{M}$ palmitate for 8 hours compared to those treated with $300 \mu \mathrm{M}$ oleate. (D) Graph showing significantly decreased isocitrate dehydrogenase (IDH) activity in NCMs treated with $300 \mu \mathrm{M}$ palmitate for 8 hours compared to those treated with $300 \mu \mathrm{M}$ oleate. (E) Western blot showing no difference in IDH3a protein levels in NCMs treated with $300 \mu \mathrm{M}$ palmitate for 8 hours compared to those treated with $300 \mu \mathrm{M}$ oleate. Histone was used as loading control.

cycle derived from said acetyl-CoA. We found that pre-treatment with palmitate led to a small non-significant decrease in ASM production compared to cells pre-treated with oleate (data not shown) suggesting that $\beta$-oxidation may be impaired by palmitate. However, we found that etomoxir only partially prevented radioactivity in ASM samples. Indeed, ASM samples from cells treated with etomoxir only had a $\sim 2$ fold reduction in radioactivity (data not shown). In contrast, etomoxir nearly abolished the production of radioactive $\mathrm{CO}_{2}(\sim 10$ fold decrease, data not shown). Because etomoxir is an inhibitor of Cpt1b, it prevents fatty acids from entering mitochondria and thus prevents mitochondrial $\beta$-oxidation. Therefore, the presence of high radioactivity in the ASM samples from cells treated with etomoxir suggests that oleate and palmitate are being oxidized to a significant degree in peroxisomes or alternatively, that full-length fatty acids are partially soluble in $1 \mathrm{M}$ perchloric acid. This data implies that in our hands, ASM analysis is not entirely specific for mitochondrial $\beta$-oxidation.

Therefore we established a novel technique in which we measured water-soluble metabolites by separating full-length fatty acids in an organic phase while measuring watersoluble metabolites (WSMs) in the aqueous phase. WSMs include acetyl-CoA produced by $\beta$-oxidation of fatty acids as well as any of the downstream citric acid cycle intermediates derived from the latter acetyl-CoA. We were able to nearly abolish radioactivity in WSM samples from cells treated with etomoxir suggesting that this technique is much more specific for measuring mitochondrial $\beta$-oxidation (data not shown). Interestingly, we found that treating NCMs with $300 \mu \mathrm{M}$ palmitate for 8 hours led to a significant decrease in WSMs 


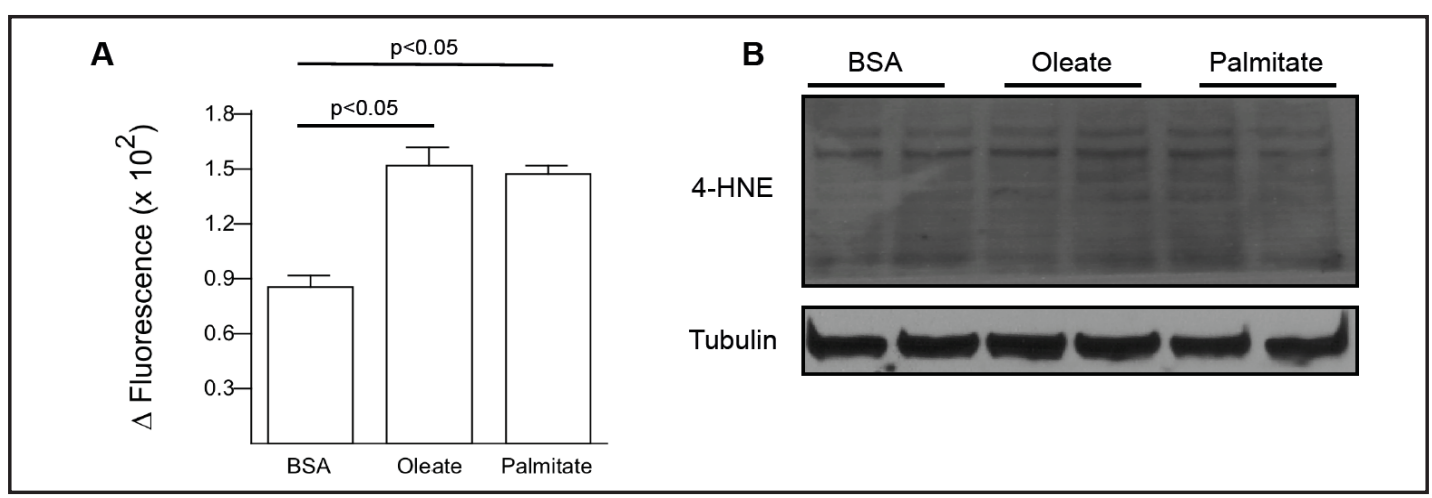

Fig. 4. $300 \mu \mathrm{M}$ oleate or palmitate for 8 hours induces increased ROS generation but not overt oxidative stress in primary neonatal cardiomyocytes (NCMs). (A) Graph showing significantly increased DCFDA fluorescence in NCMs treated with $300 \mu \mathrm{M}$ oleate or $300 \mu \mathrm{M}$ palmitate for 8 hours compared to those treated with BSA. (B) Western blot showing no difference in 4-HNE immunoreactivity in NCMs treated with BSA, $300 \mu \mathrm{M}$ oleate, or $300 \mu \mathrm{M}$ palmitate for 8 hours. Tubulin was used as loading control.

compared to NCMs treated with $300 \mu \mathrm{M}$ oleate for the same time (Fig. 2A), suggesting that palmitate impairs $\beta$-oxidation in NCMs. Co-administration of carnitine did not rescue the palmitate mediated decrease in WSM production (Fig. 2B). Similar results were found in H9C2 cardiomyoblasts. Indeed, palmitate significantly reduced WSM production in H9C2s (data not shown).

\section{Palmitate impairs citric acid cycle flux}

To assess if palmitate had any effect on the citric acid cycle (CAC) we measured the rate of acetyl-CoA oxidation. Acetyl-CoA is oxidized by the citric acid cycle which is downstream of, and thus independent of $\beta$-oxidation. Therefore acetyl-CoA oxidation is a measure of citric acid cycle flux. Interestingly, we found a significant decrease in acetyl-CoA oxidation in $300 \mu \mathrm{M}$ palmitate treated NCMs compared to NCMs treated with $300 \mu \mathrm{M}$ oleate (Fig. 3A) suggesting that palmitate also impairs citric acid cycle flux.

Aconitase is a key proximal CAC enzyme that has been previously shown to be differentially regulated in diabetic hearts [28], therefore we were interested in evaluating if palmitate had any effect on this enzyme. Aconitase catalyzes the conversion of citrate to isocitrate through the intermediate formation of aconitate. We measured both forward activity (citrate to aconitate) and reverse activity (isocitrate to aconitate) in NCMs treated with either oleate or palmitate for 8 hours. We found that there was no significant difference in forward activity between oleate and palmitate treated NCMs (Fig. 3B). In contrast, palmitate led to a significantly enhanced reverse activity (Fig. 3C). This increased reverse activity consequently causes a net decrease in isocitrate levels thus contributing to decreased CAC flux.

Next we evaluated IDH activity because it is widely considered the rate-limiting step of the CAC [34]. We found that there was a significant decrease in IDH activity in palmitate treated NCMs compared to oleate treated NCMs (Fig. 3D). To determine if the attenuated IDH activity was due to decreased protein levels, we performed a western blot to assess levels of IDH3, the mitochondrial isoform. Not surprisingly considering the short exposure time of palmitate (i.e. 8 hours), there was no decrease in IDH protein levels in palmitate treated NCMs compared to oleate treated NCMs (Fig. 3E). Therefore this indicates that palmitate negatively regulates IDH activity but not expression.

\section{Palmitate does not impair FAO through oxidative stress}

Several reports indicate that oxidative stress has deleterious effects on mitochondrial enzymes [35-38], therefore we assessed if this might be the causal mechanism for palmitate induced FAO impairment. To test this we measured ROS generation using the redox sensitive 


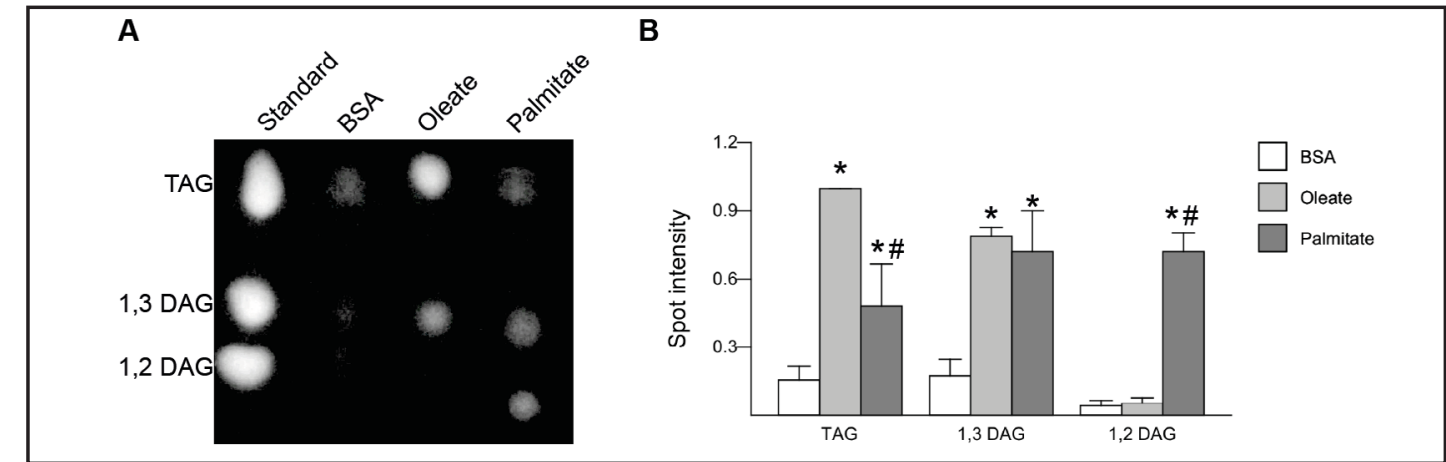

B

Fig. 5. Palmitate induces increased 1,2 diacylglycerol (DAG) in primary neonatal cardiomyocytes (NCMs). (A) Image of representative silica plate spotted with lipids isolated from cells treated with either BSA, 300 $\mu \mathrm{M}$ oleate or $300 \mu \mathrm{M}$ palmitate for 24 hours. (B) Graph showing significantly increased 1,2 DAG in NCMs treated with $300 \mu \mathrm{M}$ palmitate compared to those treated with either BSA or $300 \mu \mathrm{M}$ oleate. Graph also shows significantly increased TAG in NCMs treated with $300 \mu \mathrm{M}$ oleate compared to NCMs treated with either BSA or $300 \mu \mathrm{M}$ palmitate. * indicates $\mathrm{p}<0.05$ vs. BSA treated NCMs. \# indicates $\mathrm{p}<0.05 \mathrm{vs.} \mathrm{NCMs} \mathrm{treated} \mathrm{with}$ $300 \mu \mathrm{M}$ oleate.

dye DCFDA [31]. Interestingly we found that pre-treatment with either oleate or palmitate caused significant increases in ROS generation compared to control cells treated with BSA alone (Fig. 4A). To evaluate if this increased degree of ROS generation translated into oxidative stress we evaluated the degree of 4-Hydroxynonenal (4-HNE) protein adduct formation in cells treated with either BSA, oleate or palmitate. Interestingly there was no increase in 4-HNE protein adducts in either oleate or palmitate treated cells (Fig. 4B), indicating that the observed increase in ROS generation was not sufficient to overcome the cells' endogenous antioxidant system and suggests that this increase in ROS is not the cause of palmitate mediated FAO impairment.

Palmitate causes the accumulation of sn1,2 Diacylglycerol (1,2 DAG)

Here we showed that aconitase is differentially regulated in the same manner as observed in diabetic hearts by Lin et al. [28]. That is, they found that aconitase exhibited significantly enhanced reverse activity without a difference in forward activity just as we have reported here for palmitate treated NCMs. In that study they attributed this differential regulation to PKC- $\beta$ mediated phosphorylation of aconitase. Because PKC is a conventional isoform, which is activated by DAG, we were interested in assessing if palmitate induced an increase in intracellular DAG compared to BSA (control) or oleate treated NCMs. Interestingly, we found that palmitate exhibited significantly more 1,2 DAG than BSA and oleate treated NCMs (Fig. 5A-B). On the other hand both oleate and palmitate induced an increase in 1, 3 DAG compared to BSA control cells.

Together this data shows that palmitate significantly impairs both $\beta$-oxidation and the citric acid cycle, but does not affect Cpt1b activity. This has important implications for diabetic cardiomyopathy because impairment in FAO can lead to lipid accumulation and lipotoxicity.

\section{Discussion}

We previously demonstrated that palmitate lipotoxicity in cardiomyocytes was associated with impaired FAO and that enhancing FAO decreased lipotoxicity [33]. In addition, we also previously showed that inhibiting FAO by blocking Cpt1b either pharmacologically or genetically caused oleate, which is normally non-toxic, to induce cell death. This latter work suggests that impaired FAO can contribute to lipotoxicity likely by promoting the accumulation of toxic lipid intermediates. This led us to investigate which steps of FAO KARGER 
palmitate impairs. Here we showed that palmitate significantly impaired $\beta$-oxidation and citric acid cycle flux, with no effects on Cpt1 activity. Cpt1b catalyzes the rate-limiting step in FAO. As such it is a key site for regulation of FAO. However, we found that Cpt1b activity was not different between oleate and palmitate treated NCMs suggesting that this is not the site of palmitate induced impairment. In support of this, we found that addition of carnitine increased oleate and palmitate oxidation to equivalent degrees (i.e. both were induced $\sim 2$ fold compared to basal levels of each respective fatty acid without carnitine).

Since Cpt1b activity was not affected by palmitate, we next evaluated the degree of $\beta$-oxidation in NCMs treated with either oleate or palmitate. To this end we measured the abundance of acid soluble metabolites in cells treated with oleate and palmitate (as described in methods). We found a small reduction in ASM levels from NCMs treated with palmitate compared to those treated with oleate. However, as described in the results above, we found that ASM analysis may not be entirely specific for mitochondrial $\beta$-oxidation. To overcome this limitation we adapted the protocol used for Cpt1b activity assay in which free carnitine is separated from acylated carnitine through the use of organic/aqueous phase separation. By separating cell components into an aqueous phase and an organic phase we can separate full length fatty acids in the organic phase from acetyl-CoA and other water soluble metabolites (such as intermediates of the citric acid cycle) in the aqueous phase. Indeed this assay appears to be more specific for mitochondrial $\beta$-oxidation since we nearly abolish the production of WSMs in NCMs treated with oleate + etomoxir. Through the WSM analysis we were able to confirm a significant decrease in $\beta$-oxidation in NCMs treated with palmitate compared to those treated with oleate. This has important implications for lipotoxicity of the heart. Indeed we have previously demonstrated that impairing FAO causes toxicity in NCMs treated with non-toxic oleate. Therefore inhibition of $\beta$-oxidation may be an important cause for palmitate-mediated lipotoxicity.

The mechanism of palmitate-mediated inhibition of $\beta$-oxidation is currently unknown but may be related to palmitate mediated post-translational modifications (PTMs). Indeed fatty acids have been shown to induce PTMs in mitochondrial proteins [39]. These PTMs include phosphorylations, acetylations and palmitoylations [28, 40, 41]. Currently there is a strong debate as to whether post-translational acetylation increases or decreases $\beta$-oxidation enzyme activity. Indeed studies have shown that acetylation decreased LCAD activity and that Sirt3, a deacetylase could restore function $[42,43]$. On the other hand $\beta$-hydroxyacyl CoA dehydrogenase (HADH) has been shown to be activated with acetylation [44]. Which enzymes are post-translationally modified and what types of PTMs are regulating these enzymes will be the focus of future studies.

Next we assessed citric acid cycle flux in NCMs by measuring oxidation of acetylCoA. Interestingly, we found that palmitate significantly impaired oxidation of acetylCoA compared to oleate. Because acetyl-CoA is the product of $\beta$-oxidation, its oxidation is dependent only on citric acid cycle activity and not mitochondrial $\beta$-oxidation activity. Therefore this indicates that palmitate also inhibits the citric acid cycle. The citric acid cycle is a central hub for cellular metabolism. Indeed it is responsible for oxidation of acetylCoA not only from FAs but also from glucose derived pyruvate. The reducing equivalents produced through the latter oxidation of acetyl-CoA are necessary to maintain mitochondrial membrane potential and therefore drive oxidative phosphorylation. Also it is an important source of substrates for a variety of biosynthetic pathways. Therefore any impairment in this cycle can have profound effects on cellular metabolism. Interestingly, we found that reverse aconitase activity was significantly enhanced while forward activity was unchanged in NCMs treated with palmitate compared to those treated with oleate. The increase in reverse activity (i.e. production of aconitate from isocitrate) reduces the isocitrate levels necessary for the downstream isocitrate dehydrogenase (IDH). This reduction in substrate for IDH thus can reduce CAC flux leading to decreased oxidation of acetyl-CoA and decreased reducing equivalents. This not only impairs energy production by decreasing NADH levels necessary for ETC activity and oxidative phosphorylation but also potentially results in increased levels of substrates for de novo fatty acid synthesis.

\section{KARGER}


The finding of palmitate induced increase in reverse aconitase activity with unchanged forward activity is actually very relevant to in vivo diabetic cardiomyopathy. Indeed Lin et al. [28] actually found the same phenomenon in hearts of diabetic rats. Indeed they found that diabetic rats exhibited significantly increased reverse aconitase activity with normal forward activity and that this was due to PKC- $\beta$ mediated phosphorylation of aconitase. PKC- $\beta$ is a conventional PKC isoform which is activated by diacylglycerol (DAG). Therefore we evaluated if palmitate induced an increase in DAG compared to oleate. Interestingly, we found that palmitate resulted in significantly less TAG but significantly more DAG than oleate in NCMs. Moreover we found that the real difference was in the levels of the sn 1,2 DAG isomer and not the sn1,3 DAG isomer. This is of utmost importance because previous studies have shown that it is the 1,2 and not the 1,3 DAG isomer that is responsible for PKC activation [45]. Together this data shows that CAC flux is impaired by palmitate at least in part by a net decrease in aconitase mediated isocitrate production and that this may be occurring through PKC mediated phosphorylation of aconitase.

Next we assessed if isocitrate dehydrogenase activity was affected by palmitate. Interestingly we found that palmitate significantly attenuated IDH activity as well. Importantly, the decrease in IDH activity in palmitate treated cells was independent of the altered aconitase activity because the IDH activity assay measured the formation of $\alpha$-ketoglutarate from supplied, not endogenous, isocitrate. To verify that this was not due to targeted protein degradation, we assessed IDH protein levels. Not surprisingly, considering the short 8-hour incubation time, we found no difference in protein levels. Reduced IDH activity has a major impact on CAC flux as it catalyzes an irreversible reaction producing both $\mathrm{CO}_{2}$ and NADH. The mechanism of IDH inhibition by palmitate is currently unknown.

Oxidative stress is a major contributing factor to diabetic cardiomyopathy and several studies have shown that oxidative stress is deleterious to mitochondrial enzyme function [35-38]. Therefore we assessed ROS generation using the DCFDA assay and oxidative stress by determination of 4-HNE immunoreactivity. 4-HNE immunoreactivity is a marker for oxidative stress because lipid peroxidation by ROS leads to increased levels of 4-HNE adducts on cellular proteins [46]. Interestingly we found that palmitate significantly increased ROS generation. However, this is unlikely the cause of IDH inhibition for 2 reasons. Firstly, the degree of ROS generation was equivalent to oleate induced ROS generation. Since IDH activity was decreased in palmitate compared to oleate treated NCMs yet both oleate and palmitate induced ROS generation to similar degrees, it is unlikely that this as a cause for inhibition. Secondly we found no evidence of oxidative stress in oleate or palmitate treated cells (as determined by 4-HNE immunoreactivity) compared to control (BSA treated) cells indicating that the elevated ROS observed did not overwhelm the cells endogenous antioxidant potential. This is supported by a previous study which showed that palmitate mediated cell death was not due to ROS [47]. Together this data demonstrates that palmitate attenuates both $\beta$-oxidation and citric acid cycle flux likely in part through DAG mediated PKC activation. The fact that palmitate is one of the most abundant fatty acids in human diets suggests that this may be a contributing factor to the lipotoxicity observed in diabetic cardiomyopathy.

\section{Acknowledgements}

This work was supported by the Heart and Stroke foundation of Canada (G14-0005849) and the Montreal Heart Institute Foundation.

\section{Disclosure Statement}

No conflict of interest. 


\section{Cellular Physiology Cell Physiol Biochem 2016;40:969-981 and Biochemistry \begin{tabular}{l|l} 
DOI: 10.1159/000453154 & (c) 2016 The Author(s). Published by S. Karger AG, Basel \\
www.karger.com/cpb
\end{tabular} \\ Haffar et al.: Palmitate Impairs Lipid Metabolism}

\section{References}

1 Grundy SM, Benjamin IJ, Burke GL, Chait A, Eckel RH, Howard BV, Mitch W, Smith SC, Jr., Sowers JR: Diabetes and cardiovascular disease: a statement for healthcare professionals from the American Heart Association. Circulation 1999;100:1134-1146.

2 Ussher JR: The role of cardiac lipotoxicity in the pathogenesis of diabetic cardiomyopathy. Expert Rev Cardiovasc Ther 2014;12:345-358.

3 Finck BN, Han X, Courtois M, Aimond F, Nerbonne JM, Kovacs A, Gross RW, Kelly DP: A critical role for PPARalpha-mediated lipotoxicity in the pathogenesis of diabetic cardiomyopathy: modulation by dietary fat content. Proc Natl Acad Sci USA 2003;100:1226-1231.

4 Basu R, Oudit GY, Wang X, Zhang L, Ussher JR, Lopaschuk GD, Kassiri Z: Type 1 diabetic cardiomyopathy in the Akita (Ins2WT/C96Y) mouse model is characterized by lipotoxicity and diastolic dysfunction with preserved systolic function. Am J Physiol Heart Circ Physiol 2009;297:H2096-2108.

5 van de Weijer T, Schrauwen-Hinderling VB, Schrauwen P: Lipotoxicity in type 2 diabetic cardiomyopathy. Cardiovasc Res 2011;92:10-18.

6 Kok BP, Brindley DN: Myocardial fatty acid metabolism and lipotoxicity in the setting of insulin resistance. Heart Fail Clin 2012;8:643-661.

7 Pulinilkunnil T, Kienesberger PC, Nagendran J, Waller TJ, Young ME, Kershaw EE, Korbutt G, Haemmerle G, Zechner R, Dyck JR: Myocardial adipose triglyceride lipase overexpression protects diabetic mice from the development of lipotoxic cardiomyopathy. Diabetes 2013;62:1464-1477.

8 Gaborit B, Kober F, Jacquier A, Moro PJ, Cuisset T, Boullu S, Dadoun F, Alessi MC, Morange P, Clement K, Bernard M, Dutour A: Assessment of epicardial fat volume and myocardial triglyceride content in severely obese subjects: relationship to metabolic profile, cardiac function and visceral fat. Int J Obes (Lond) 2012;36:422-430.

9 Rijzewijk LJ, van der Meer RW, Smit JW, Diamant M, Bax JJ, Hammer S, Romijn JA, de Roos A, Lamb HJ: Myocardial steatosis is an independent predictor of diastolic dysfunction in type 2 diabetes mellitus. J Am Coll Cardiol 2008;52:1793-1799.

10 Utz W, Engeli S, Haufe S, Kast P, Hermsdorf M, Wiesner S, Pofahl M, Traber J, Luft FC, Boschmann M, SchulzMenger J, Jordan J: Myocardial steatosis, cardiac remodelling and fitness in insulin-sensitive and insulinresistant obese women. Heart 2011;97:1585-1589.

11 Korosoglou G, Humpert PM, Ahrens J, Oikonomou D, Osman NF, Gitsioudis G, Buss SJ, Steen H, Schnackenburg B, Bierhaus A, Nawroth PP, Katus HA: Left ventricular diastolic function in type 2 diabetes mellitus is associated with myocardial triglyceride content but not with impaired myocardial perfusion reserve. J Magn Reson Imaging 2012;35:804-811.

12 Mazumder PK, O'Neill BT, Roberts MW, Buchanan J, Yun UJ, Cooksey RC, Boudina S, Abel ED: Impaired cardiac efficiency and increased fatty acid oxidation in insulin-resistant ob/ob mouse hearts. Diabetes 2004;53:2366-2374.

13 Buchanan J, Mazumder PK, Hu P, Chakrabarti G, Roberts MW, Yun UJ, Cooksey RC, Litwin SE, Abel ED: Reduced cardiac efficiency and altered substrate metabolism precedes the onset of hyperglycemia and contractile dysfunction in two mouse models of insulin resistance and obesity. Endocrinology 2005;146:5341-5349.

14 Turcotte LP, Swenberger JR, Zavitz Tucker M, Yee AJ: Increased fatty acid uptake and altered fatty acid metabolism in insulin-resistant muscle of obese Zucker rats. Diabetes 2001;50:1389-1396.

15 Holloway GP, Snook LA, Harris RJ, Glatz JF, Luiken JJ, Bonen A: In obese Zucker rats, lipids accumulate in the heart despite normal mitochondrial content, morphology and long-chain fatty acid oxidation. J Physiol 2011;589:169-180.

16 Chen V, Ianuzzo CD, Fong BC, Spitzer JJ: The effects of acute and chronic diabetes on myocardial metabolism in rats. Diabetes 1984;33:1078-1084.

17 Young ME, Guthrie PH, Razeghi P, Leighton B, Abbasi S, Patil S, Youker KA, Taegtmeyer H: Impaired long-chain fatty acid oxidation and contractile dysfunction in the obese Zucker rat heart. Diabetes 2002;51:2587-2595.

18 Hartvig P, Waldenstrom A, Wikstrom G, Zielinski T, Martinussen HJ, Carslsten J, Voipio-Pulkki LM, Lundqvist H, Bjurling P, Nagren K, et al.: The diabetic heart: a porcine model evaluated with positron emission tomography using 1-11C-palmitate and 3-11C-pyruvate. Diabetes Res 1989;12:1-5. 


\section{Cellular Physiology Cell Physiol Biochem 2016;40:969-981 \begin{tabular}{l|l|l|} 
and and 10.1159/000453154 & $\begin{array}{l}\text { C) 2016 The Author(s). Published by S. Karger AG, Basel } \\
\text { www.karger.com/cpb }\end{array}$
\end{tabular} \\ Haffar et al.: Palmitate Impairs Lipid Metabolism}

19 Anderson EJ, Kypson AP, Rodriguez E, Anderson CA, Lehr EJ, Neufer PD: Substrate-specific derangements in mitochondrial metabolism and redox balance in the atrium of the type 2 diabetic human heart. J Am Coll Cardiol 2009;54:1891-1898.

20 Montaigne D, Marechal X, Coisne A, Debry N, Modine T, Fayad G, Potelle C, El Arid JM, Mouton S, Sebti Y, Duez H, Preau S, Remy-Jouet I, Zerimech F, Koussa M, Richard V, Neviere R, Edme JL, Lefebvre P, Staels B: Myocardial contractile dysfunction is associated with impaired mitochondrial function and dynamics in type 2 diabetic but not in obese patients. Circulation 2014;130:554-564.

21 Chatham JC, Gao ZP, Forder JR: Impact of 1 wk of diabetes on the regulation of myocardial carbohydrate and fatty acid oxidation. Am J Physiol 1999;277:E342-351.

22 Murthy VK, Jameson M, Todd GL, Shipp JC: Effects of chronic non-ketotic diabetes and aging on myocardial function and fatty acid oxidation. J Diabet Complications 1990;4:26-34.

23 Kuo TH, Moore KH, Giacomelli F, Wiener J: Defective oxidative metabolism of heart mitochondria from genetically diabetic mice. Diabetes 1983;32:781-787.

24 Pierce GN, Dhalla NS: Heart mitochondrial function in chronic experimental diabetes in rats. Can J Cardiol 1985;1:48-54.

25 Tanaka Y, Konno N, Kako KJ: Mitochondrial dysfunction observed in situ in cardiomyocytes of rats in experimental diabetes. Cardiovasc Res 1992;26:409-414.

26 Flarsheim CE, Grupp IL, Matlib MA: Mitochondrial dysfunction accompanies diastolic dysfunction in diabetic rat heart. Am J Physiol 1996;271:H192-202.

27 Croston TL, Thapa D, Holden AA, Tveter KJ, Lewis SE, Shepherd DL, Nichols CE, Long DM, Olfert IM, Jagannathan R, Hollander JM: Functional deficiencies of subsarcolemmal mitochondria in the type 2 diabetic human heart. Am J Physiol Heart Circ Physiol 2014;307:H54-65.

28 Lin G, Brownsey RW, MacLeod KM: Regulation of mitochondrial aconitase by phosphorylation in diabetic rat heart. Cell Mol Life Sci 2009;66:919-932.

29 Haffar T, Berube-Simard FA, Tardif J-C, Bousette N: Saturated fatty acids induce endoplasmic reticulum stress in primary cardiomyocytes. Endoplasm Reticul Stress Dis DOI:10.1515/ersc-2015-000453-66.

30 He L, Kim T, Long Q, Liu J, Wang P, Zhou Y, Ding Y, Prasain J, Wood PA, Yang Q: Carnitine palmitoyltransferase-1b deficiency aggravates pressure overload-induced cardiac hypertrophy caused by lipotoxicity. Circulation 2012;126:1705-1716.

31 Wang H, Joseph JA: Quantifying cellular oxidative stress by dichlorofluorescein assay using microplate reader. Free Radic Biol Med 1999;27:612-616.

32 Haffar T, Berube-Simard FA, Bousette N: Cardiomyocyte lipotoxicity is mediated by Il- 6 and causes downregulation of PPARs. Biochem Biophys Res Commun 2015;459:54-59.

33 Haffar T, Berube-Simard F, Bousette N: Impaired fatty acid oxidation as a cause for lipotoxicity in cardiomyocytes. Biochem Biophys Res Commun DOI:10.1016/j.bbrc.2015.10.162

34 Cupp JR, McAlister-Henn L: NAD(+)-dependent isocitrate dehydrogenase. Cloning, nucleotide sequence, and disruption of the IDH2 gene from Saccharomyces cerevisiae. J Biol Chem 1991;266:22199-22205.

35 Yan LJ, Levine RL, Sohal RS: Oxidative damage during aging targets mitochondrial aconitase. Proc Natl Acad Sci USA 1997;94:11168-11172.

36 Bulteau AL, Ikeda-Saito M, Szweda LI: Redox-dependent modulation of aconitase activity in intact mitochondria. Biochemistry 2003;42:14846-14855.

37 Kanski J, Behring A, Pelling J, Schoneich C: Proteomic identification of 3-nitrotyrosine-containing rat cardiac proteins: effects of biological aging. Am J Physiol Heart Circ Physiol 2005;288:H371-381.

38 Ago T, Kuroda J, Pain J, Fu C, Li H, Sadoshima J: Upregulation of Nox4 by hypertrophic stimuli promotes apoptosis and mitochondrial dysfunction in cardiac myocytes. Circ Res 2010;106:1253-1264.

39 Pougovkina O, te Brinke H, Ofman R, van Cruchten AG, Kulik W, Wanders RJ, Houten SM, de Boer VC: Mitochondrial protein acetylation is driven by acetyl-CoA from fatty acid oxidation. Hum Mol Genet 2014;23:3513-3522.

40 Marquez J, Lee SR, Kim N, Han J: Post-Translational Modifications of Cardiac Mitochondrial Proteins in Cardiovascular Disease: Not Lost in Translation. Korean Circ J 2016;46:1-12.

41 Kostiuk MA, Corvi MM, Keller BO, Plummer G, Prescher JA, Hangauer MJ, Bertozzi CR, Rajaiah G, Falck JR, Berthiaume LG: Identification of palmitoylated mitochondrial proteins using a bio-orthogonal azidopalmitate analogue. FASEB J 2008;22:721-732. 


\section{Cellular Physiology Cell Physiol Biochem 2016;40:969-981 \begin{tabular}{ll|l} 
DOI: 10.1159/000453154 & $\begin{array}{l}\text { O 2016 The Author(s). Published by S. Karger AG, Basel } \\
\text { www.karger.com/cpb }\end{array}$
\end{tabular} \\ Haffar et al.: Palmitate Impairs Lipid Metabolism}

42 Bharathi SS, Zhang Y, Mohsen AW, Uppala R, Balasubramani M, Schreiber E, Uechi G, Beck ME, Rardin MJ, Vockley J, Verdin E, Gibson BW, Hirschey MD, Goetzman ES: Sirtuin 3 (SIRT3) protein regulates long-chain acyl-CoA dehydrogenase by deacetylating conserved lysines near the active site. J Biol Chem 2013;288:33837-33847.

43 Hirschey MD, Shimazu T, Goetzman E, Jing E, Schwer B, Lombard DB, Grueter CA, Harris C, Biddinger S, Ilkayeva OR, Stevens RD, Li Y, Saha AK, Ruderman NB, Bain JR, Newgard CB, Farese RV, Jr., Alt FW, Kahn CR, Verdin E: SIRT3 regulates mitochondrial fatty-acid oxidation by reversible enzyme deacetylation. Nature 2010;464:121-125.

44 Zhao S, Xu W, Jiang W, Yu W, Lin Y, Zhang T, Yao J, Zhou L, Zeng Y, Li H, Li Y, Shi J, An W, Hancock SM, He F, Qin L, Chin J, Yang P, Chen X, Lei Q, Xiong Y, Guan KL: Regulation of cellular metabolism by protein lysine acetylation. Science 2010;327:1000-1004.

45 Rando RR, Young N: The stereospecific activation of protein kinase C. Biochem Biophys Res Commun 1984;122:818-823.

46 Poli G, Biasi F, Leonarduzzi G: 4-Hydroxynonenal-protein adducts: A reliable biomarker of lipid oxidation in liver diseases. Mol Aspects Med 2008;29:67-71.

47 Hickson-Bick DL, Sparagna GC, Buja LM, McMillin JB: Palmitate-induced apoptosis in neonatal cardiomyocytes is not dependent on the generation of ROS. Am J Physiol Heart Circ Physiol 2002;282:H656-664. 